\title{
Ductility Calculation of Prefabricated Shear Wall with Rabbet-Unbond Horizontal Connection
}

\author{
Chongfang Sun $\mathbb{D},,^{1,2}$ Shuting Liang $\mathbb{D}^{2},{ }^{2}$ Xiaojun $\mathrm{Zhu}^{3}$ Yamin Song, ${ }^{2}$ and Dongyue Wu $\mathbb{I D}^{4}$ \\ ${ }^{1}$ Jinan Rail Transit Group Co. Ltd., Jinan, Shandong 250101, China \\ ${ }^{2}$ School of Civil Engineering, Southeast University, Nanjing 210018, China \\ ${ }^{3}$ Architectural Design and Research Institute Ltd., Southeast University, Nanjing 210018, China \\ ${ }^{4}$ School of Civil Engineering and Architecture, Jiangsu University of Science and Technology, Zhenjiang 212000, China \\ Correspondence should be addressed to Shuting Liang; stliang@seu.edu.cn
}

Received 17 August 2017; Accepted 31 October 2017; Published 3 April 2018

Academic Editor: Chiara Bedon

Copyright (c) 2018 Chongfang Sun et al. This is an open access article distributed under the Creative Commons Attribution License, which permits unrestricted use, distribution, and reproduction in any medium, provided the original work is properly cited.

Considering the effect of confined end-zone and unbonded reinforcement, the yield curvature and ultimate curvature of rabbetunbond horizontal connection (RHC) shear wall were calculated. Based on the curvature calculation result, the yield displacement and ultimate displacement were calculated using displacement superposition, which were compared with test values. The result showed that theoretical values were slightly smaller than test values; however, on the whole, both were in good agreement. The author studied the effect of unbonded reinforcement on yield displacement and ultimate displacement, and the result showed that the effect on ultimate displacement is more pronounced than yield displacement. The present work could be useful for the design of new prefabricated shear wall.

\section{Introduction}

In recent years, due to high industrialized level, good quality, convenient installation, energy conservation, and environment protection, the precast concrete structure is widely used. In particular, the prefabricated shear wall structure with large rigidity and great bearing capacity is the first choice for highrise housings. In this regard, China has made policies to promote the development of the prefabricated shear wall structure [1], and many institutes and universities have carried out the relevant research $[2,3]$; meanwhile, they cooperate with the national housing industrialization bases $[4,5]$ and applies the structure in some estate development projects as demonstration $[6,7]$. What is more, the implementing subjects continue rise, for example, the prefabricated concrete shear wall structure system of Zhongnan Group [8]. For the prefabricated shear wall structure, the horizontal connection in the structure is the key to ensure structural integrity and seismic performance [9], and for this purpose, the authors invent a new horizontal connection [10] whose bearing capacity has been studied; however, the ductility which unbonded reinforcement can improve has not been studied.

To date, addressing the ductility calculation of different shear wall structures, many engineers or scholars have made contributions. For the conventional cast-in-situ shear wall, Si et al. [11] proposed displacement ductility calculation method considering the effect of axial compression ratio, shear span ratio, confined end-zone, and stirrup eigenvalue. Park et al. [12] deduced the crack curvature, yield curvature, peak curvature, and ultimate curvature of flexure-dominated shear wall with concentrated end-zone reinforcements and uniformly web reinforcements along the cross section. For high-performance concrete shear wall, Liang et al. [13] deduced the crack-bending moment and curvature, yieldbending moment and curvature, peak-bending moment and curvature, and ultimate-bending moment and curvature. For prefabricated shear wall, Chen [14] deduced the formula of crack-bending moment and curvature, yield-bending moment and curvature, peak-bending moment and curvature, and ultimate-bending moment and curvature. 


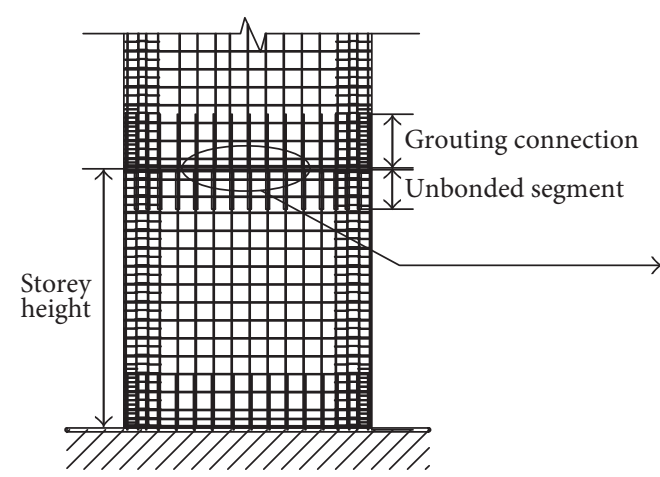

(a)

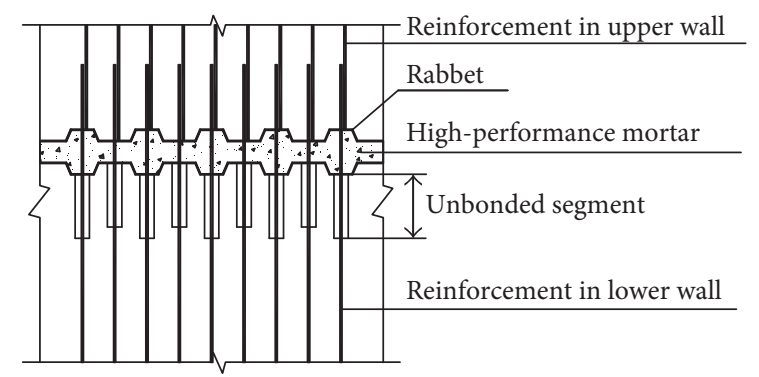

(b)

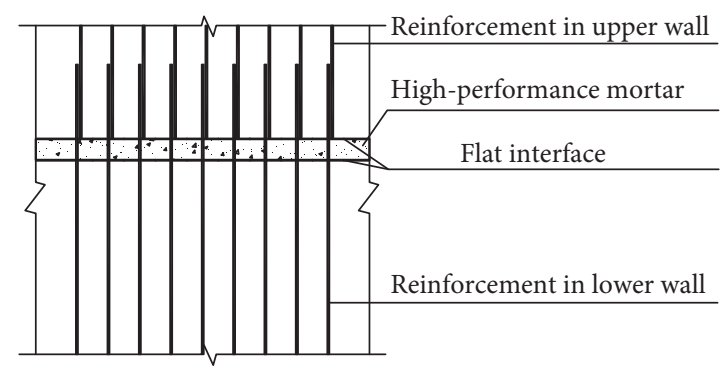

(c)

Figure 1: (a) Prefabricated shear wall, (b) the RHC details, and (c) conventional connection details. Note: For the sake of clarity, the lateral web reinforcements in the upper and lower walls are not shown in (b) and (c).

Therefore, here, firstly, for the newly horizontal connection, considering the effect of confined end-zone and unbonded reinforcement, yield curvature and ultimate curvature are calculated, which prepares for displacement calculation. And then, yield displacement and ultimate displacement are calculated using displacement superposition, which is verified by the test values. Finally, the effects of unbonded reinforcement on yield displacement and ultimate displacement are studied.

\section{Rabbet-Unbond Horizontal Connection}

The arrangement of the rabbet-unbond horizontal connection (RHC) is shown in Figures 1(a) and 1(b). The reinforcements reserved in the lower wall are connected with those in the upper wall by a well-developed grouting-connection technology. The two walls are integrated by filling high-performance mortar into the space between a pair of trapezoidal rabbets. Compared with the conventional connection (Figure 1(c)), a segment reinforcement of RHC in the lower wall is left unbonded to increase the ductility and energy dissipation of the assembled structure, and the trapezoidal rabbets are used to enhance the connection's shear capacity.

\section{Curvature Calculation of RHC Shear Wall}

This section calculates yield curvature and ultimate curvature considering effect of confined end-zone and unbonded reinforcement, meanwhile, which prepares for calculation of yield displacement and ultimate displacement in Section 4.

\subsection{Deformation Coordination Equation}

3.1.1. Strain Lag of Unbonded Reinforcement. According to test phenomenon of literature [15], compared with the bonded specimen, unbonded specimen's crack width and length are greater under the same loading, which states that the unbonded cross section's neutral axis is closer to compressed zone, as shown in Figure 2. Assuming that bending moments $M$ of the two sections in Figure 2 are equal and the tensile reinforcements do not yield, we can get $A_{s} E_{s} \varepsilon_{s 1} Z_{1}=A_{s} E_{s} \varepsilon_{s 2} Z_{2}=M$, where $A_{s}$ and $E_{s}$ are the cross section's area and Young's modulus of the tensile reinforcement, respectively, $\varepsilon_{s 1}, \varepsilon_{s 2}$ are the tensile reinforcement strains in the bonded cross section and the unbonded cross section, respectively, $Z_{1}$ and $Z_{2}$ are the lever of the bonded cross section and the unbonded cross section, respectively, the subscripts 1 and 2 denote the bonded and unbonded. Apparently, under a constant moment $M, Z_{2}>Z_{1}$ leads to $\varepsilon_{s 2}<\varepsilon_{s 1}$, and this is called "strain lag."

Regarding the "strain lag," the unbonded cross section's average strain distribution is no longer linear but bilinear (Figure 3).

3.1.2. Deformation Coordination Region. For the bonded shear wall, the ductility' calculation is based on the plane section assumption and the deformation coordination assumption between reinforcement and concrete. Because the maximum moment locates at the bottom of the shear wall, the plane section assumption regards a rectangular region at the bottom as the basic deformation coordination 


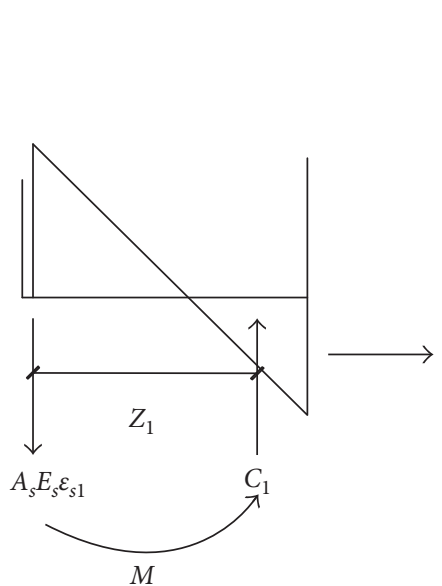

(a)

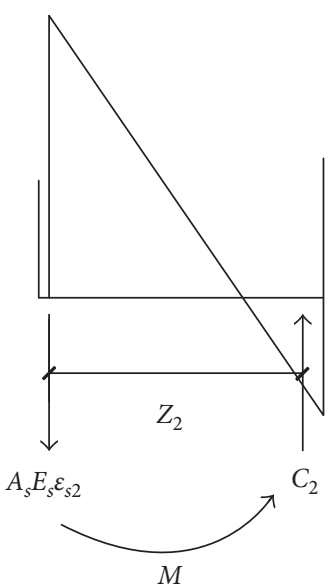

(b)

FiguRE 2: Force in (a) bonded cross section and (b) unbonded cross section. Note: $C_{1}$ and $C_{2}$ represent the resultant force of compressive concrete, respectively.

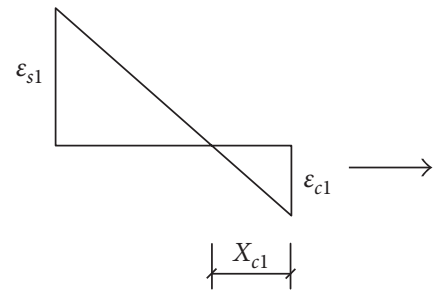

(a)

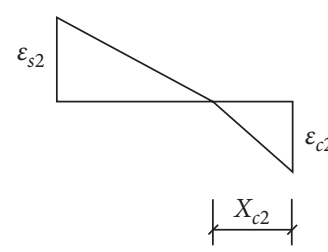

(b)

FIgURE 3: Average strain distributions in (a) bonded cross section and (b) unbonded cross section.

region (Figure 4(a)), and the deformation coordination equation is

$$
\frac{x_{c 1}}{h_{0}-x_{c 1}}=\frac{\varepsilon_{c 1} l_{c 1}}{\varepsilon_{s 1} l_{s 1}}
$$

where $x_{c 1}$ is the height of the compressed zone in the cross section of the bonded shear wall (Figure $3(\mathrm{a})$ ). $h_{0}$ is the effective height of the cross section. $\varepsilon_{c 1}$ and $\varepsilon_{s 1}$ are the edge strain of the compressed concrete and the strain of the tensile reinforcement in the cross section of the bonded shear wall, respectively (Figure $3(\mathrm{a})$ ). $l_{c 1}$ and $l_{s 1}$ are the heights of the compressed zone and the tensile zone of the deformation coordination region of the bonded shear wall, respectively (see Figure 4(a)). Because $l_{c 1}=l_{s 1}$, the deformation coordination (1) is reexpressed as

$$
\frac{x_{c 1}}{h_{0}-x_{c 1}}=\frac{\varepsilon_{c 1}}{\varepsilon_{s 1}} .
$$

For the unbonded shear wall, we assume that in the compressed zone of the wall, the deformation of the unbonded reinforcement is consistent with the concrete deformation, but in the tensile zone of the wall, the deformation of the unbonded reinforcement is not consistent with the concrete deformation. In this regard, the traditional plane section assumption is no longer applicable, and the shape of the deformation coordination region is changed from the rectangular to the trapezoidal (Figure 4(b)); however, the strain of the tensile reinforcement in the trapezoidal is uniformly distributed.

3.1.3. Deformation Coordination Equation. For the sake of convenience, regard the concrete edge compressive strain of the maximum bending moment cross section as the calculated value, correspondingly, the equivalent compressive height of $l_{c 2}$ [16] is denoted as $l_{e}$. It is worth mentioned that the traditional plane section assumption is still applicable beyond trapezoidal deformation region, and the boundary condition of the region is linear. Thus, assuming that the deformation of the trapezoidal region also obeys the linear distribution along the cross section height, we can get the deformation coordination equation:

$$
\frac{x_{c 2}}{h_{0}-x_{c 2}}=\frac{\varepsilon_{c 2} l_{e}}{\varepsilon_{s 2} l_{s 2}},
$$

where $x_{c 2}$ is the height of the compressed zone in the cross section of the unbonded shear wall (Figure 3(b)), $\varepsilon_{c 2}$ and $\varepsilon_{s 2}$ are the edge strain of the compressed concrete and the strain of the tensile reinforcement in the cross section of the unbonded shear wall, respectively (Figure $3(\mathrm{~b})$ ), $l_{s 2}$ is the height of the tensile zone of the deformation coordination region of the unbonded shear wall, and it equals the unbonded length, and $l_{e}$ is the equivalent compressive height of the unbonded shear wall, derived from the loading tests of partial unbonded reinforced 


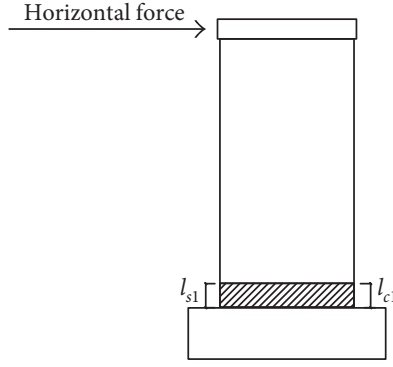

(a)

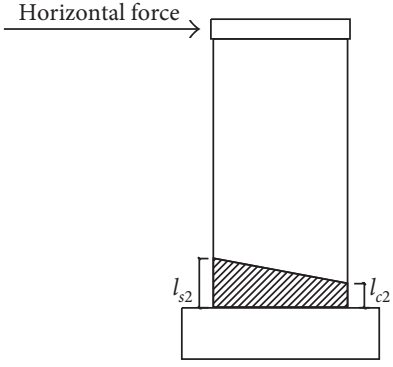

(b)

FIgURE 4: Deformation coordination region of (a) bonded shear wall and (b) unbonded shear wall.

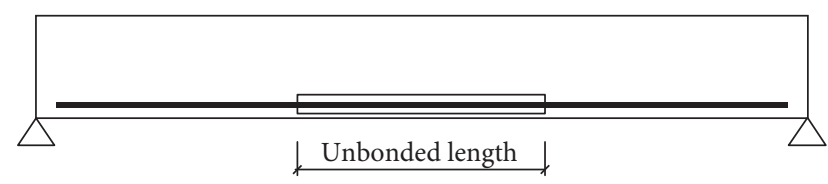

FIGURE 5: Partial unbonded reinforced concrete beam.

concrete beams with pure bending regions [16], as shown in Figure 5.

The formula of $l_{e}$ is obtained in the following method: In tests of partial unbonded reinforced concrete beam, strain values of the top concrete under each level load are recorded, and the total deformation $\Delta l_{c}$ of top concrete corresponding to unbonded length can be calculated. The average strain value of the top concrete under the same level load within pure bending region is expressed as $\varepsilon_{c}$. Divide $\Delta l_{c}$ by $\varepsilon_{c}$, and we can get the equivalent compressive height. Take the average value of equivalent compressive heights under all level loads as the final equivalent compressive height. By fitting, the equivalent compressive height formula is expressed as

$$
l_{e}= \begin{cases}0.74 l_{s 2}, & 90 \mathrm{~mm}<l_{s 2}<900 \mathrm{~mm} \\ 32.81+0.09 l_{s 2}, & 900 \mathrm{~mm}<l_{s 2}<1575 \mathrm{~mm} .\end{cases}
$$

Since the shear wall can be regarded as the cantilever beam, the author employs $l_{e}$ to calculate the ductility of RHC shear wall. Here, ignore the effect of axial force acting on the shear wall.

3.2. Assumption. The assumptions to calculate the ductility of RHC shear wall are stated as follows:

(1) The concrete is based on the plane section assumption and its tensile strength is not considered.

(2) The compressed stress-strain curve of concrete and stress calculation of the vertical reinforcement refer to China code "Code for the design of concrete structures (GB 50010-2010, 2010)." The ultimate tensile strain of the vertical reinforcement is 0.01 .

(3) In compressed zone, the unbonded reinforcement deformation is coordinated with the concrete deformation.

(4) The deformation coordination region in the unbonded segment is from rectangular to trapezoidal. The tensile reinforcement strain in the trapezoidal region is uniformly distributed. Deformation in the trapezoidal region obeys linear distribution.
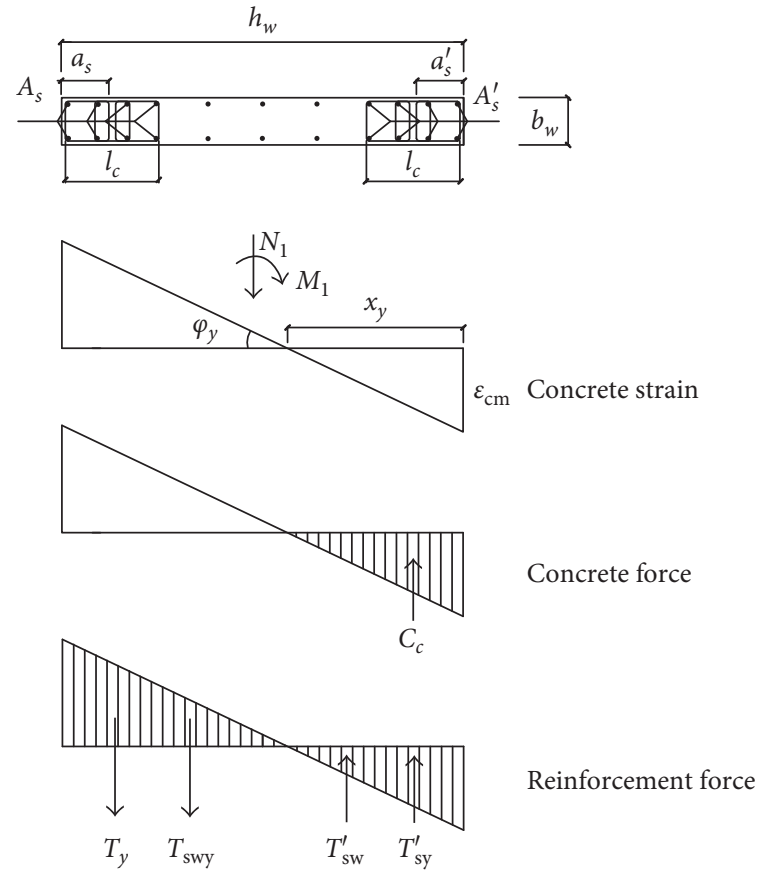

FIgURE 6: Stress and strain distribution profile in the yield state.

3.3. Yield Curvature. In the yield state, the lateral deformation of compressive concrete is small, so stirrup stress is small, and stirrup restraint in the confined end-zone is not considered. The stress-strain relationship of concrete adopts unconfined stress-strain relationship. Assume that when bonded reinforcement segments in confined end-zone yield, the shear wall yields. Stress of the compressive concrete is assumed to be the linear triangle distribution. Deformation of reinforcement and concrete in compressive zone is assumed to be consistent. Stress and strain distribution in the yield state is shown in Figure 6.

According to the force equilibrium, the following equation can be obtained as follows:

$$
N_{1}+T_{y}+T_{\text {swy }}=C_{c}+T_{s w}^{\prime}+T_{s y}^{\prime},
$$

where $N_{1}$ is the axial force acting on the shear wall's cross section in the yield state. $T_{y}$ is the yield force of vertical reinforcement in the tensile zone which can be defined as $T_{s}=f_{y} A_{s}$, where $f_{y}$ is the yield stress of tensile reinforcement. $T_{\text {swy }}$ is the tensile force of web reinforcements in the 
tensile zone which can be defined as $T_{\text {swy }}=\rho_{w} b_{w}\left(h_{w 0}-\right.$ $\left.x_{y}\right) f_{\mathrm{yw}} / 2$, where $\rho_{w}$ is the reinforcement ratio of web reinforcement; $b_{w}$ is the cross section width; $h_{w 0}$ is the effective height of the cross section; $x_{y}$ is the depth of compressive zone; and $f_{\mathrm{yw}}$ is the yield stress of web reinforcement. $C_{c}$ is the compressive force of concrete in the compressive zone which can be defined as $C_{c}=b_{w} E_{c} x_{y}^{2} \varphi_{y} / 2$, where $E_{c}$ is the elastic modulus of concrete. $T_{\text {sw }}^{\prime}$ is the compressive force of web reinforcements in the compressive zone which can be defined as $T_{s w}^{\prime}=\rho_{w} b_{w}\left(x_{y}-a_{s}^{\prime}\right)^{2} E_{s} \varphi_{y} / 2$, where $a_{s}^{\prime}$ is the distance of compressed reinforcement resultant force to compressed edge. $T_{\text {sy }}^{\prime}$ is the compressive force of vertical reinforcement in compressive constraint zone which here can be defined as $T_{\text {sy }}^{\prime}=E_{s}\left(x_{y}-a_{s}^{\prime}\right) \varphi_{y} A_{s}^{\prime}$, where $A_{s}^{\prime}$ is the compressed reinforcement cross section area.

According to assumption (1), the deformation coordination equation is

$$
\frac{x_{y}}{h_{w 0}-x_{y}}=\frac{\varepsilon_{\mathrm{cm}} l_{e}}{\varepsilon_{y} l_{s 2}}
$$

where $\varepsilon_{\mathrm{cm}}$ is the concrete compressive strain and $\varepsilon_{y}$ is the yield strain of reinforcement.

Solve above equations and $\varphi_{y}=\varepsilon_{\mathrm{cm}} / x_{y}$ can be calculated according to the concrete strain profile in Figure 6.

3.4. Ultimate Curvature. In the ultimate state, the lateral deformation of compressive concrete is great, so stirrup restraint in confined end-zone should be considered. The stress-strain relationship of concrete adopts the confined stress-strain relationship. Assume that when the compressive concrete strain in confined, end-zone reaches ultimate compressive strain and shear wall reaches the ultimate state. Deformation of reinforcement and concrete in compressive zone is assumed to be consistent. What is more, compressive reinforcements are assumed to yield. The compression effect of unconfined concrete is not considered. Stress and strain distribution in ultimate state is shown in Figure 7.

According to the force equilibrium, the following equation can be obtained:

$$
N_{2}+T_{s}+T_{\text {swu }}=C_{\mathrm{cc}}+C_{\mathrm{uc}}+T_{\mathrm{su}}^{\prime},
$$

where $N_{2}$ is the axial force acting on the shear wall's cross section in the ultimate state. $T_{s}$ is the tensile force of vertical reinforcement in the tensile constraint zone which can be defined as $T_{s}=\sigma_{s} A_{s}$, where $\sigma_{s}$ is the tensile stress of vertical reinforcements in the constraint zone which can be defined as $\sigma_{s}=E_{s} \varepsilon_{\mathrm{ccu}} l_{e} / l_{s 2}\left(h_{w 0} \beta / x-1\right)$ from (6), where $\varepsilon_{\mathrm{ccu}}$ is the ultimate compressive strain of confined concrete; $\beta$ is the coefficient corresponding to the rectangular stress block, refer to China code "Code for design of concrete structures (GB 50010-2010, 2010)"; $x$ is the depth of the compressive zone in rectangular stress block which can be defined as $x=x_{u} \beta_{1}$. $T_{\text {swu }}$ is the tensile force of web reinforcements in the tensile zone which can be defined as $T_{\mathrm{swu}}=f_{\mathrm{yw}} b_{\mathrm{w}} \rho_{w}\left(h_{w 0}-1.5 x\right)$. $C_{c c}$ is the compressive force of confined concrete. $C_{\mathrm{uc}}$ is the compressive force of unconfined concrete. $C_{\mathrm{cc}}$ and $C_{\mathrm{uc}}$ have different formulas for different eccentric compression states. $T_{\mathrm{su}}^{\prime}$ is the compressive force of vertical reinforcement in the

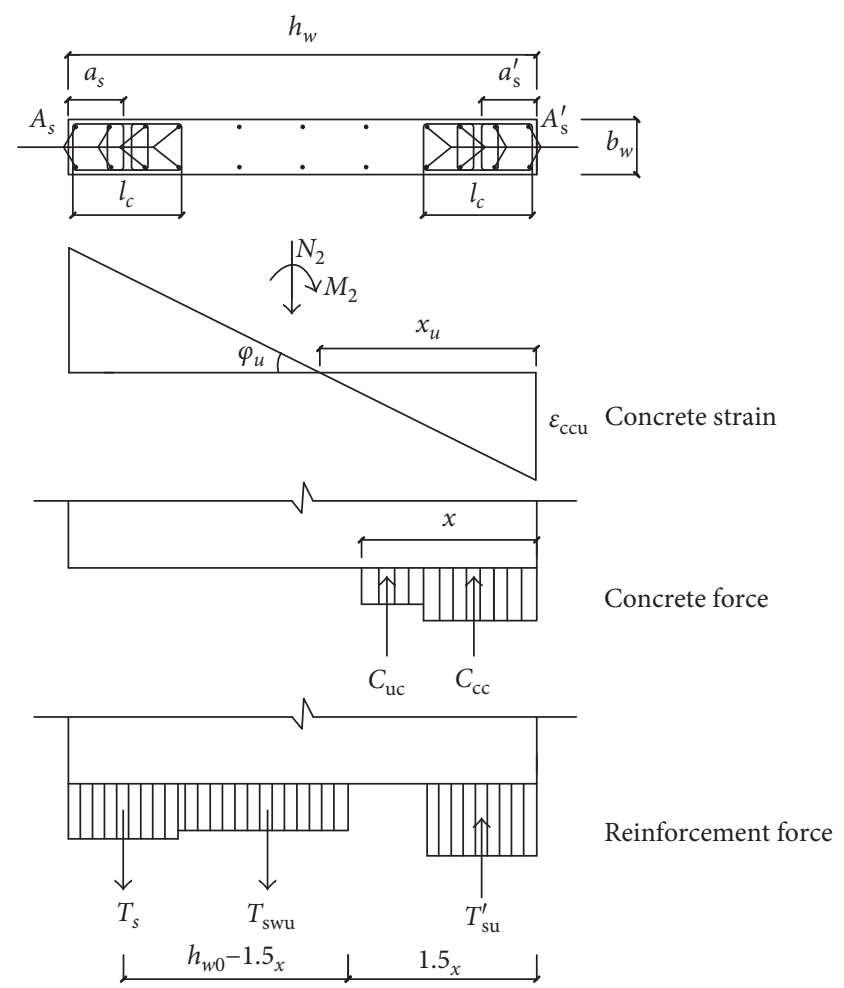

FIGURE 7: Stress and strain distribution profile in the ultimate state.

compressive constraint zone which here can be defined as $T_{\mathrm{su}}^{\prime}=\sigma_{s}^{\prime} A_{s}^{\prime}$, where $\sigma_{s}^{\prime}$ is the compressive stress of vertical reinforcements.

The constitutive law of confined concrete referring to literature [17] is as follows:

$$
\begin{aligned}
\varepsilon_{\mathrm{cc}} & =\left(1+3.5 \lambda_{v}\right) \varepsilon_{c 0}, \\
\varepsilon_{\mathrm{ccu}} & =\left(2.34+2.49 \lambda_{v}^{0.73}\right) \varepsilon_{\mathrm{cc}}, \\
f_{\mathrm{cc}} & =\left(1+1.79 \lambda_{v}\right) f_{c},
\end{aligned}
$$

where $\varepsilon_{\mathrm{cc}}$ is the peak compressive strain of confined concrete, $\lambda_{v}$ is the stirrup eigenvalue, $\varepsilon_{c 0}$ is the peak compressive strain of unconfined concrete and it is set as $0.0018, f_{\mathrm{cc}}$ is the axial compressive strength of confined concrete, and $f_{c}$ is the axial compressive strength of unconfined concrete.

According to assumption (1), the deformation coordination equation is

$$
\frac{x_{u}}{h_{w 0}-x_{u}}=\frac{\varepsilon_{\mathrm{ccu}} l_{e}}{\varepsilon_{s} l_{s 2}} .
$$

From (7) and (9), $x$ can be calculated. Different $x$ leads to different eccentric compression states and different ultimate curvatures; then, the explanations are as follows:

(1) When $x \leq x_{b}$, the wall is in large eccentric compression, $T_{s}=T_{s}^{\prime}=f_{y} A_{s}$, where $x_{b}$ is the boundary depth of the compressive zone. This situation consists of two states: $x_{b}>x>l_{c}$ and $x \leq l_{c}$.

(a) When $x_{b}>x>l_{c}, N_{2}=C_{\mathrm{cc}}+C_{\mathrm{uc}}-T_{\mathrm{sw}}$, where $C_{\mathrm{cc}}=\alpha f_{\mathrm{cc}} b_{w} l_{c}, \alpha$ is the coefficient corresponding 


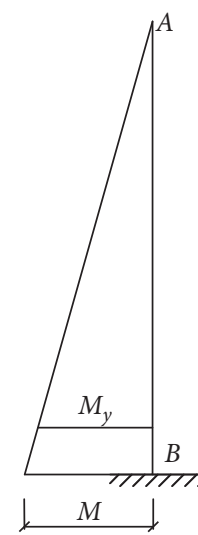

(a)

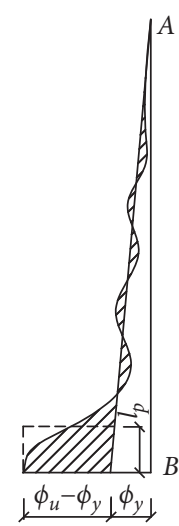

(b)

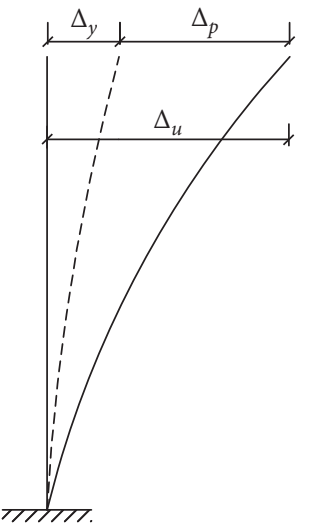

(c)

Figure 8: (a) Bending moment, (b) curvature, and (c) lateral displacement of cantilever shear wall.

to constraint zone length and it is set as 0.8 and $l_{c}$ is the confinement depth. $C_{\mathrm{uc}}=f_{c} b_{w}\left(x-l_{c}\right)$.

(b) When $x \leq l_{c}, N_{2}=C_{\mathrm{cc}}-T_{\mathrm{sw}}$, where $C_{\mathrm{uc}}=0, C_{\mathrm{cc}}=$ $\alpha f_{\mathrm{cc}} b_{w} x$.

(2) When $x>x_{b}$, the wall is in small eccentric compression, $N_{2}=C_{\mathrm{cc}}+C_{\mathrm{uc}}+T_{s}^{\prime}-T_{s}$, where here $T_{s}^{\prime}=f_{y}^{\prime} A_{s}^{\prime}$. This situation consists of two states: $x>l_{c}$ and $x_{b}<x \leq l_{c}$.

(a) When $x>l_{c}, C_{\mathrm{cc}}=\alpha f_{\mathrm{cc}} b_{w} l_{c}, C_{\mathrm{uc}}=f_{c} b_{w}\left(x-l_{c}\right)$, the equation about $x$ can be obtained as:

$$
\begin{gathered}
f_{c} b_{w} x^{2}+\left(\alpha f_{\mathrm{cc}} b_{w} l_{c}-f_{c} b_{w} l_{c}+f_{y}^{\prime} A_{s}^{\prime}+A_{s} E_{s} \varepsilon_{\mathrm{ccu}} \frac{l_{e}}{l_{s 2}}-N_{2}\right) \\
\cdot x-A_{s} E_{s} \varepsilon_{\mathrm{ccu}} h_{w 0} \beta_{1} \frac{l_{e}}{l_{s 2}}=0 .
\end{gathered}
$$

When $x_{b}<x \leq l_{c}, N_{2}=C_{\mathrm{cc}}+T_{s}^{\prime}-T_{s}$, where $C_{\mathrm{uc}}=0$, $C_{\mathrm{cc}}=\alpha f_{\mathrm{cc}} b_{w} x$, the equation about $x$ can be obtained as

$$
\begin{gathered}
\alpha f_{\mathrm{cc}} b_{w} x^{2}+\left(f_{y}^{\prime} A_{s}^{\prime}+A_{s} E_{s} \varepsilon_{\mathrm{ccu}} \frac{l_{e}}{l_{s 2}}-N_{2}\right) \\
\cdot x-A_{s} E_{s} \varepsilon_{\mathrm{ccu}} h_{w 0} \beta_{1} \frac{l_{e}}{l_{s 2}}=0 .
\end{gathered}
$$

Solve the above equations, and finally we can obtain the ultimate curvature $\varphi_{u}=\varepsilon_{\mathrm{ccu}} / x_{u}$.

\section{Calculation of Displacement Ductility}

The displacement ductility $\mu \Delta$ is defined as $\mu \Delta=\Delta_{u} / \Delta_{y}$, where $\Delta_{u}$ is the ultimate displacement and $\Delta_{y}$ is the yield displacement.

Assume that wall's displacement consists of two parts approximately: one part is the displacement that the wall generates resisting external force when all reinforcements are bonded, and assume the wall is not a rigid body and another part is the displacement that elongation of unbonded reinforcements leads the wall to generate when the wall is RHC wall, and assume the wall is a rigid body.

$$
\Delta_{y}=\Delta_{y 1}+\Delta_{y 2}, \Delta_{u}=\Delta_{u 1}+\Delta_{u 2},
$$

where $\Delta_{y 1}$ and $\Delta_{u 1}$ are yield displacement and ultimate displacement that the wall generates resisting external force when all reinforcements are bonded, and assume the wall is not a rigid body, respectively. $\Delta_{y 2}$ and $\Delta_{u 2}$ are yield displacement and ultimate displacement that elongation of unbonded reinforcements leads the wall to generate when the wall is RHC wall, and assume the wall is a rigid body, respectively.

4.1. Calculation of $\Delta_{y 1}, \Delta_{u 1}$. The shear wall can be regarded as a cantilever member. In a cantilever member, the curvature distribution of plastic hinge region is very irregular (Figure 8(b)). The height of plastic hinge region can be determined by the curvature distribution along the wall height.

Based on the displacement equivalent principle in maximum bending moment region, the curvature distribution of plastic hinge region can be simplified, which consists of two parts: the plastic deformation region and the elastic deformation region.

Curvature is defined as the corner angle unit height, so the corner angle relative to the base section at any height $h$ can be expressed as $\theta_{h}=\int_{0}^{h} \varphi d x$.

Therefore, the lateral displacement relative to the base section at any height $h$ can be expressed as $\Delta_{h}=\int_{0}^{h} x \varphi d x$.

Define that when the base section of cantilever shear wall yields, shear wall yields. The yield curvature is linear distribution along the wall height $H$ (Figure $8(\mathrm{~b})$ ). The curvature in the top section is zero, and the curvature in the base section is the yield curvature $\varphi_{y}$ (Figure 9), and the resulting equation can be expressed as $x / H=\varphi / \varphi_{y}$.

Applying above equations, the yield displacement can be derived as follows:

$$
\Delta_{y 1}=\int_{0}^{H} \varphi_{y} \frac{x^{2}}{H} d x=\varphi_{y} \frac{H^{2}}{3} .
$$

Assume that when shear wall reaches the ultimate state, there is a equivalent plastic hinge region height $l_{p}$ at 


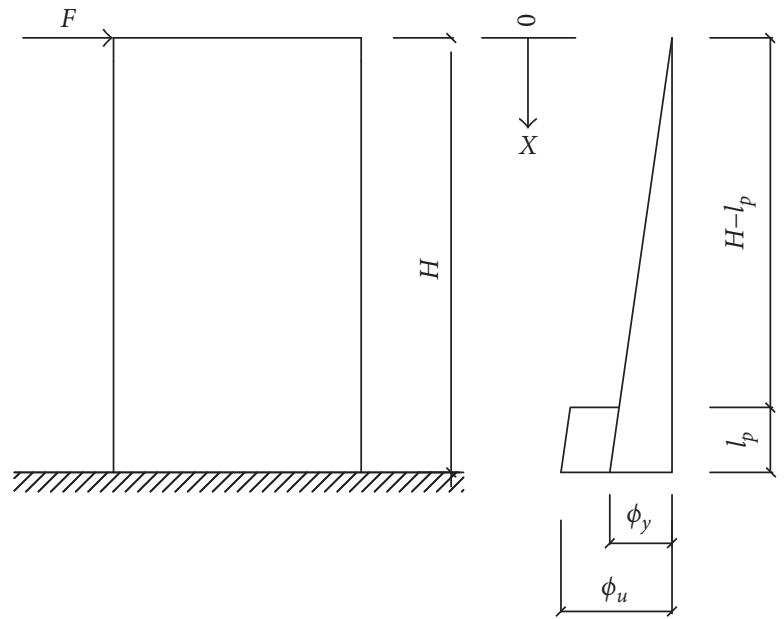

FIgURE 9: Curvature of cantilever shear wall.

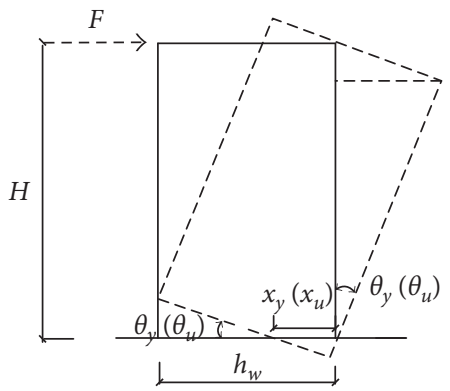

(a)
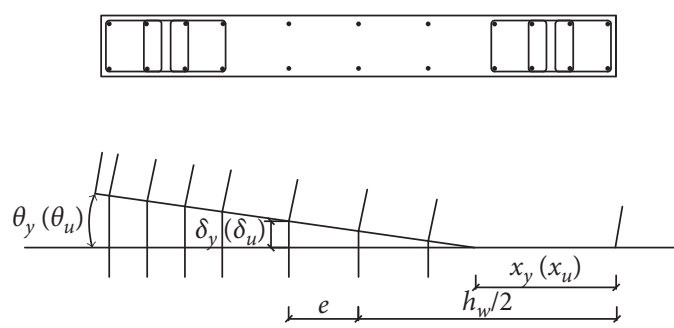

(b)

FIGURE 10: (a) Rigid body rotation and (b) unbonded reinforcement deformation of RHC shear wall.

the wall base, in which plastic curvature is equal to the largest plastic curvature $\varphi_{p}$, and the resulting equation can be expressed as $\varphi_{p}=\varphi_{u}-\varphi_{y}$.

Applying above equations, the ultimate displacement can be derived as follows:

$$
\begin{aligned}
\Delta_{u 1}= & \int_{0}^{H} \varphi_{y} \frac{x^{2}}{H} d x+\int_{H-l_{p}}^{H}\left(\varphi_{u}-\varphi_{y}\right) x d x=\varphi_{y} \frac{H^{2}}{3} \\
& +\left(\varphi_{u}-\varphi_{y}\right) \frac{2 H l_{p}-l_{p}^{2}}{2}
\end{aligned}
$$

where $l_{p}$ is the equivalent plastic hinge region height which can be defined as $l_{p}=\left(0.20+0.044 H / h_{w}\right) h_{w}$, where $h_{w}$ is the cross section length. The formula of $l_{p}$ is generally a good estimate for RC shear walls [9].

\subsection{Calculation of $\Delta_{y 2}, \Delta_{u 2}$}

4.2.1. Calculation of $\Delta_{y 2}$. When calculating $\Delta_{y 2}$, as shown in Figure 10(a), assume that the shear wall is a rigid body and the deformation of bonded reinforcement is ignored, the yield displacement can be expressed approximately as $\Delta_{y 2}=\theta_{y} \times H$, where $\theta_{y}$ is the wall's corner angle, as shown in Figure 10(b), which can be expressed as $\theta_{y}=\delta_{y} / h_{w} / 2-x_{y} \pm e$, where $x_{y}$ is the compressive zone depth in the yield state obtained by Section 3.3 approximately, $e$ is the distance of unbonded reinforcement to the cross section's geometric center, and $\delta_{y}$ is the elongation of unbonded reinforcement.

When unbonded reinforcements in tensile confined endzone yield, elongation of unbonded reinforcements can be expressed as $\delta_{y}=\varepsilon_{y} \times l_{s}$.

Applying above equations, the yield displacement can be derived as follows:

$$
\Delta_{y 2}=\frac{\varepsilon_{y} l_{s} H}{h_{w} / 2-x_{y} \pm e} .
$$

4.2.2. Calculation of $\Delta_{u 2}$. When calculating $\Delta_{u 2}$, as shown in Figure 10(a), assume that the shear wall is a rigid body and the elongation of bonded reinforcement is ignored, the ultimate displacement can be expressed approximately as $\Delta_{u 2}=\theta_{u} \times$ $H$, where $\theta_{u}$ is the corner angle at wall base, which can be expressed as $\theta_{u}=\delta_{u} / h_{w} / 2-x_{u} \pm e$, where $x_{u}$ is the compressive zone depth in the ultimate state obtained by Section 3.4 approximately and $\delta_{u}$ is the elongation of unbonded reinforcement.

For $\delta_{u}$, according to the provision 4.2.4 in China code "Code for design of concrete structures (GB 50010-2010, 2010)," 


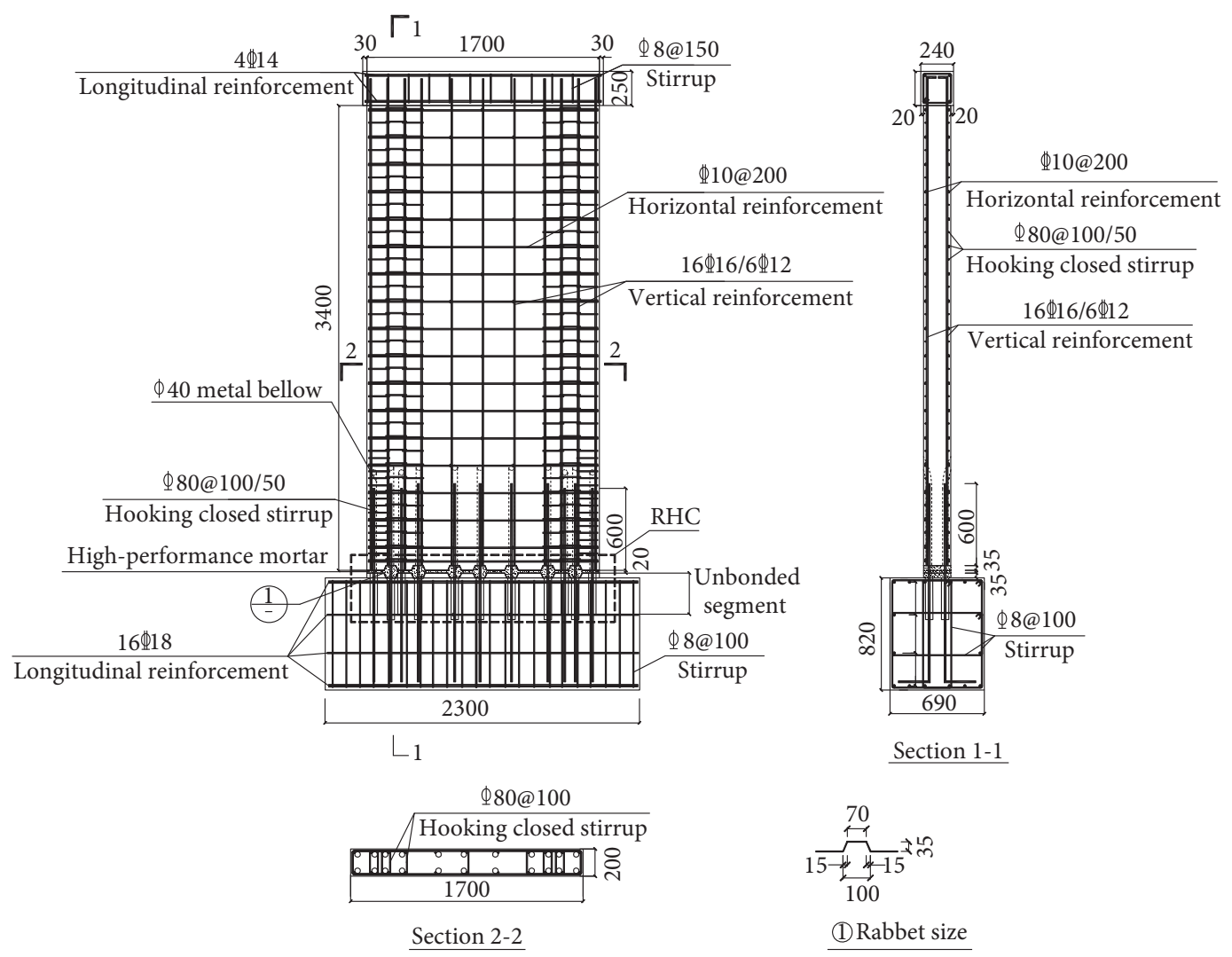

FIGURE 11: Dimension and reinforcement details of the RHC shear wall specimen (unit: $\mathrm{mm}$ ).

the gross elongation of HRB400 ordinary reinforcement under the largest force should not be less than 7.5\%. When calculating $\Delta_{u 2}$, we assume that the deformation of unbonded reinforcements in tensile confined end-zone reaches the minimum elongation percentage $\delta_{\mathrm{gt}}=7.5 \%$; the elongation can be expressed as $\delta_{u}=\delta_{\mathrm{gt}} \times l_{s}$.

Applying above equations, the ultimate displacement can be expressed as

$$
\Delta_{u 2}=\frac{\delta_{\mathrm{gt}} l_{s} H}{h_{w} / 2-x_{u} \pm e} .
$$

\section{Verification of Ductility}

Two full-scale specimens (RHC-1, RHC-2) are designed and tested. The RHC specimen is composed of a base and a wall. The wall has a height, length, and thickness of $3.4 \mathrm{~m}, 1.7 \mathrm{~m}$, and $0.2 \mathrm{~m}$, as shown in Figure 11. The base has a length, width, and height of $2.3 \mathrm{~m}, 0.69 \mathrm{~m}$, and $0.82 \mathrm{~m}$. The grouting region is located in the wall. The unbonded segment at the vertical reinforcements is located in the base. Based on the finite element simulation results of specimens before test, select the unbonded length at the vertical reinforcement as $300 \mathrm{~mm}$. The horizontal connection is located between the wall and the base. Considering the vertical reinforcement intensity of confined end-zones and construction of metal bellows, seven rabbets are set up symmetrically at connection. The rabbet's size is shown in Figure 11. High-performance mortar is grouted in metal bellows and connection. Two specimens have the same details of reinforcement and size, and the difference is the axial compression ratio with 0.1 of RHC- 1 and 0.2 of RHC- 2 .

5.1. Material Properties. All of the materials (concrete, steel, and mortar) employed in the tests are selected based on China code "Code for design of concrete structures (GB 50010-2010, 2010).” The grade of concrete is C35, which denotes that the ultimate compressive strength of the cubic concrete specimens $(15 \mathrm{~cm} \times 15 \mathrm{~cm} \times 15 \mathrm{~cm})$ cured in standard conditions is $35 \mathrm{MPa}$, and its Poisson's ratio is 0.2 . Here, six cubic concrete specimens are tested.

The grade of steel in the tests is HRB400, where HRB denotes hot-rolled ribbed-steel bar and the number 400 denotes the yield strength. Its elastic modulus is $200 \mathrm{GPa}$ and Poisson's ratio is 0.3 , and three sets of steels with different diameters $(d=10 \mathrm{~mm}, 12 \mathrm{~mm}$, and $16 \mathrm{~mm})$ are tested.

The high-performance mortar is tested $(160 \mathrm{~mm} \times$ $40 \mathrm{~mm} \times 40 \mathrm{~mm}$ ) with a type of $\mathrm{H}-80$, which is a characteristic of early strength, high strength, no shrinkage, and high fluidity.

The mechanical parameters of all materials are presented in Tables 1-3.

5.2. Test Setup. The quasistatic cyclic tests of the RHC shear wall are performed. Axial load is applied by tensioning prestressed reinforcement strands, and the lateral load is applied by the $150 \mathrm{t}$ hydraulic actuator. The loading protocol employed 
TABLE 1: Mechanical property of concrete.

\begin{tabular}{lccc}
\hline $\begin{array}{l}\text { Specimen } \\
\text { number }\end{array}$ & $\begin{array}{c}\text { Failure } \\
\text { load (kN) }\end{array}$ & $\begin{array}{c}\text { Compressive } \\
\text { strength }(\mathrm{MPa})\end{array}$ & $\begin{array}{c}\text { Average compressive } \\
\text { strength }(\mathrm{MPa})\end{array}$ \\
\hline 1 & 880 & 39.11 & \\
2 & 910 & 40.44 & \\
3 & 822 & 36.53 & 39.86 \\
4 & 960 & 42.67 & \\
5 & 950 & 42.22 & \\
6 & 860 & 38.22 & \\
\hline
\end{tabular}

TABLE 2: Mechanical property of steel.

\begin{tabular}{lccccc}
\hline $\begin{array}{l}\text { Specimen } \\
\text { number }\end{array}$ & $\begin{array}{c}\text { Steel } \\
\text { diameter }\end{array}$ & $\begin{array}{c}\text { Yield } \\
\text { strength } \\
(\mathrm{MPa})\end{array}$ & $\begin{array}{c}\text { Ultimate } \\
\text { strength } \\
(\mathrm{MPa})\end{array}$ & $\begin{array}{c}\text { Ratio of } \\
\text { tensile } \\
\text { strength } \\
\text { to yield } \\
\text { strength }\end{array}$ & $\begin{array}{c}\text { Elongation } \\
(\%)\end{array}$ \\
\hline $1-1$ & & 445 & 625 & 1.4 & 24 \\
$1-2$ & 10 & 455 & 615 & 1.35 & 24 \\
$\begin{array}{l}\text { Average } \\
\text { value }\end{array}$ & & 450 & 620 & 1.375 & 24 \\
2-1 & & 445 & 575 & 1.29 & 25 \\
$2-2$ & 12 & 460 & 585 & 1.27 & 25 \\
$\begin{array}{l}\text { Average } \\
\text { value }\end{array}$ & & 452.5 & 580 & 1.28 & 25 \\
3-1 & & 465 & 600 & 1.29 & 25 \\
3-2 & 16 & 460 & 600 & 1.30 & 25 \\
$\begin{array}{l}\text { Average } \\
\text { value }\end{array}$ & & 462.5 & 600 & 1.295 & 25 \\
\hline
\end{tabular}

TABLE 3: Mechanical property of high-performance mortar.

\begin{tabular}{lcc}
\hline Test item & Time & Measured value \\
\hline \multirow{2}{*}{ Compressive strength $(\mathrm{MPa})$} & $1 \mathrm{~d}$ & 24.96 \\
& $28 \mathrm{~d}$ & 93.52 \\
\multirow{2}{*}{ Rupture strength $(\mathrm{MPa})$} & $1 \mathrm{~d}$ & 5.29 \\
& $28 \mathrm{~d}$ & 10.44 \\
\hline
\end{tabular}

consists of a load control procedure first and a displacement control procedure then. Moreover, four steel supports are employed on both sides of the wall symmetrically to keep the lateral stability of the specimen during the testing process. The lateral displacements of the wall are monitored by seven displacement transducers. The testing system is shown in Figure 12.

5.3. Crack Pattern and Failure Mode. For the RHC-1 specimen, the first crack observed at $210 \mathrm{kN}$ was horizontal flexural cracks when the specimen was pulled, which occurred near the bottom of the wall. The crack on the top interface of rabbet was generated at $240 \mathrm{kN}$ when the specimen was pushed. However, for the RHC-2 specimen, the first crack was observed at $270 \mathrm{kN}$ when the specimen was pushed, which occurred near the bottom of the wall. The crack on the top interface of

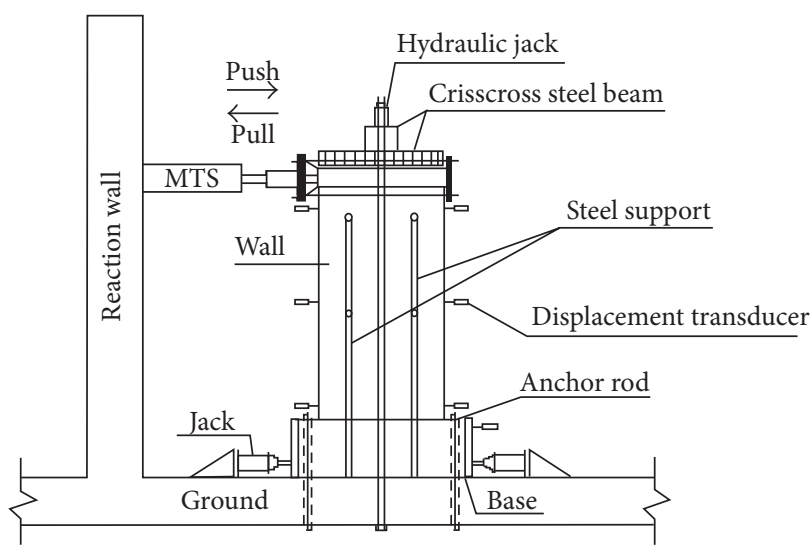

(a)

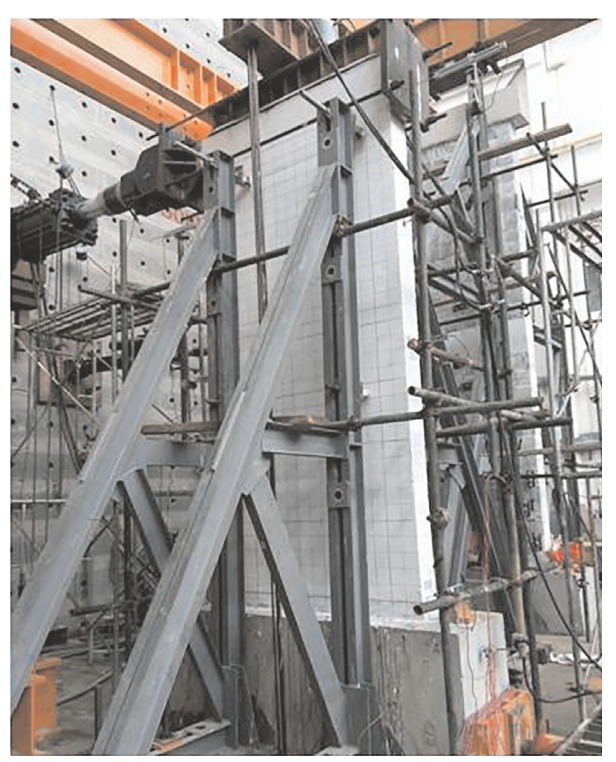

(b)

FIgURE 12: Test setup: (a) schematic and (b) photograph.

rabbet was generated at $300 \mathrm{kN}$ when the specimen was pushed.

The yield state was defined as when bonded reinforcement segments in the confined end-zone yielded, the specimen yielded. The increase of the applied load resulted in the propagation of cracks and initiation of new flexural cracks along the specimen. Further load increase extended the existing flexural cracks into flexure shear cracks and caused initiation of vertical cracks. In addition, the cracks in the center of the test specimen propagated to the compressed zone, and the crack width and the displacement increased. Finally, when the lateral resistance degenerated to $85 \%$ of the peak load, defined as the failure of the specimen, the failure mode was a typical flexural failure for each specimen, which was controlled by crushing concrete at the plastic region near the bottom of the wall. The final crack pattern and failure mode are shown in Figure 13.

From Figure 13(b), it was noted that the failure mode was not symmetrical. The reason was that the push force and pull force of hydraulic actuator during test were not symmetrical, but had little effect. 

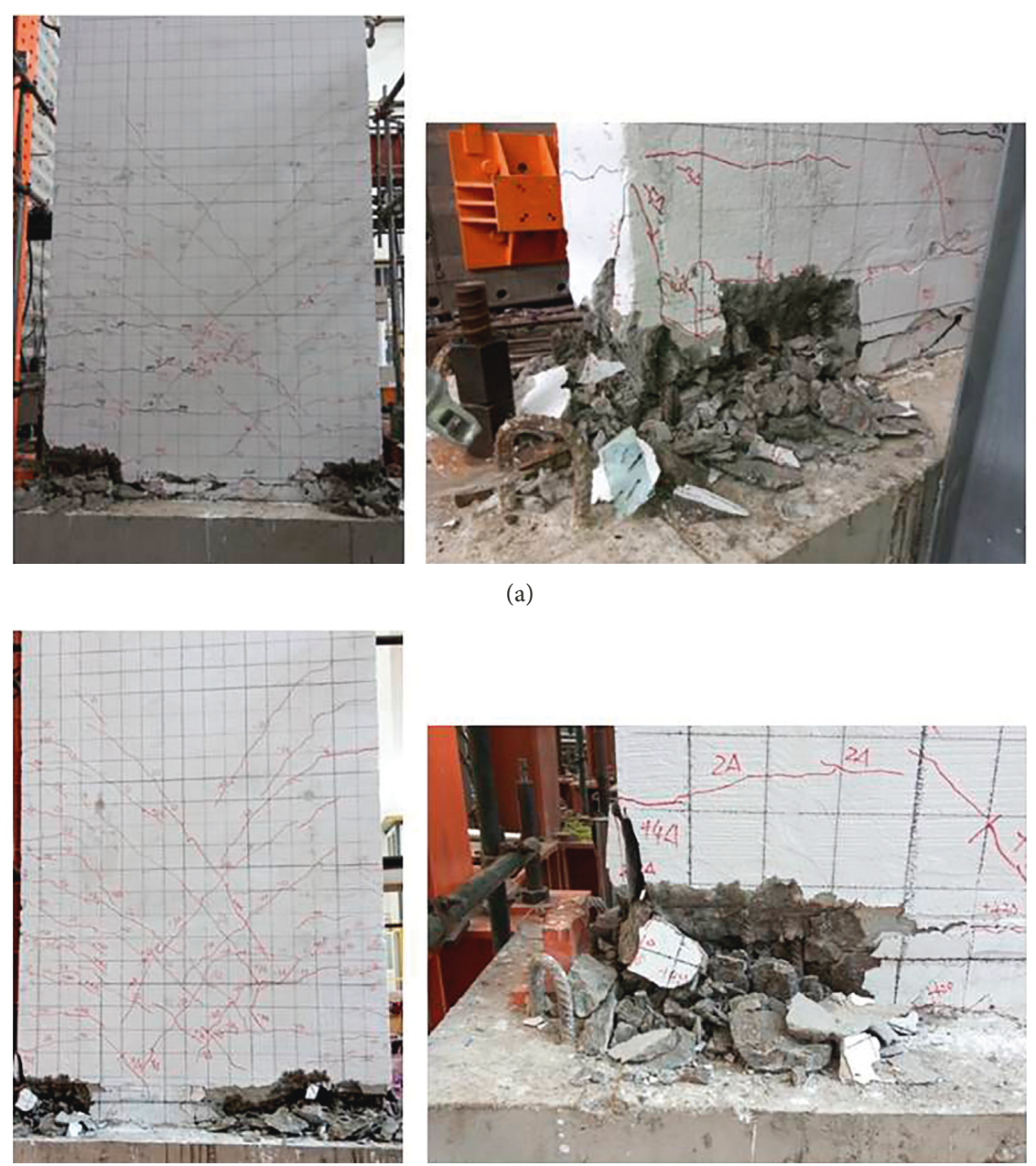

(b)

FIgURE 13: Final crack pattern and failure mode of (a) RHC-1 specimen and (b) RHC-2 specimen.

5.4. Load-Displacement Relationship. The lateral load versus top displacement curves of the two specimens is shown in Figure 14.

It is observed in Figure 14 that the number of hysteresis loop is greater and the curve is plumper in the RHC-1 specimen than in the RHC-2 specimen. The bearing capacity of the specimen is decreased by reducing the axial compression ratio, whereas the yield displacement and ultimate displacement are increased at the same time.

5.5. Bearing Capacity and Deformation. From the tests, we obtain the crack load $F_{\text {cr }}$, crack displacement $\Delta_{\text {cr }}$, yield load $F_{y}$, yield displacement $\Delta_{\mathrm{y}}$, peak load $F_{m}$, peak displacement $\Delta_{\mathrm{m}}$, ultimate load $F_{u}$, and ultimate displacement $\Delta_{u}$ of two specimens, as shown in Table 4 .

Table 4 shows that $F_{c r}, F_{y}, F_{m}$, and $F_{u}$ increase, whereas $\Delta_{c r}, \Delta_{y}, \Delta_{m}$, and $\Delta_{u}$ decrease with increase of the axial compression ratio.
5.6. Verification. Applying (13) and (15), the yield displacement can be expressed as

$$
\Delta_{y}=\varphi_{y} \frac{H^{2}}{3}+\frac{\varepsilon_{y} l_{s} H}{h_{w} / 2-x_{y} \pm e} .
$$

Applying (14) and (16), the ultimate displacement can be expressed as

$$
\Delta_{u}=\varphi_{y} \frac{H^{2}}{3}+\left(\varphi_{u}-\varphi_{y}\right) \frac{2 H l_{p}-l_{p}^{2}}{2}+\frac{\delta_{\mathrm{gt}} l_{s} H}{h_{w} / 2-x_{u} \pm e} .
$$

From (17) and (18), the yield displacement and ultimate displacement can be calculated, which are compared with test values (Table 5).

Table 5 shows that theoretical values are a little smaller than test values. There are two reasons. One is that the elongation of bonded segment is ignored when calculating $\Delta_{y 2}$ and $\Delta_{u 2}$, which leads to the theoretical values smaller. Another reason is that there exist some errors and virtual 


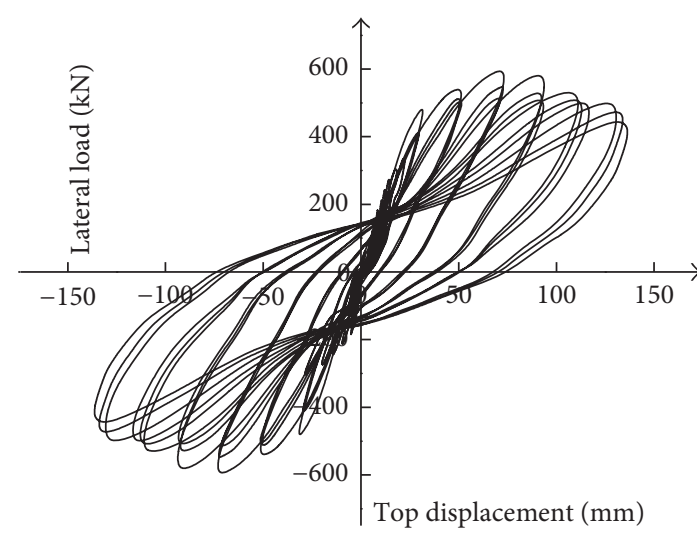

(a)

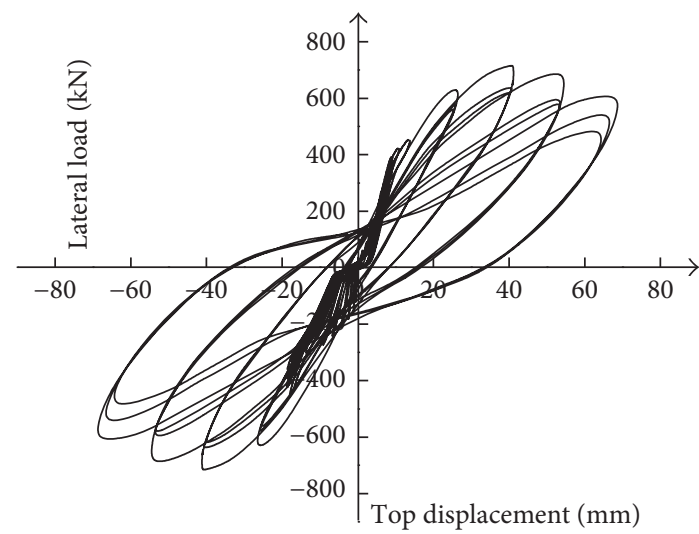

(c)

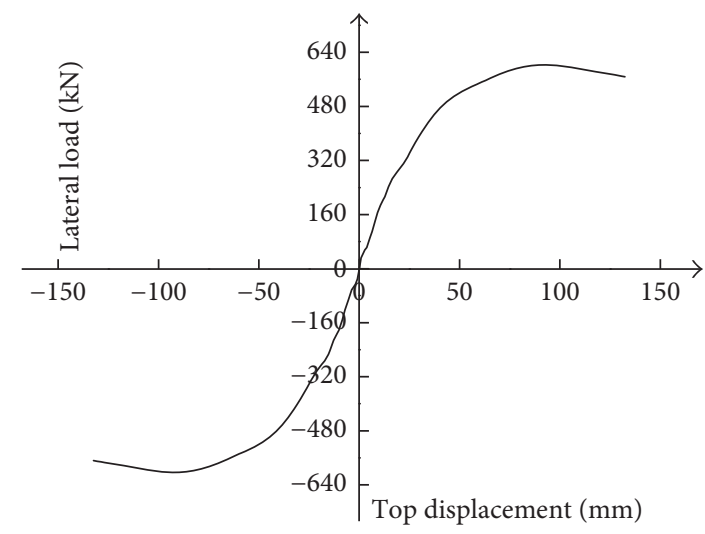

(b)

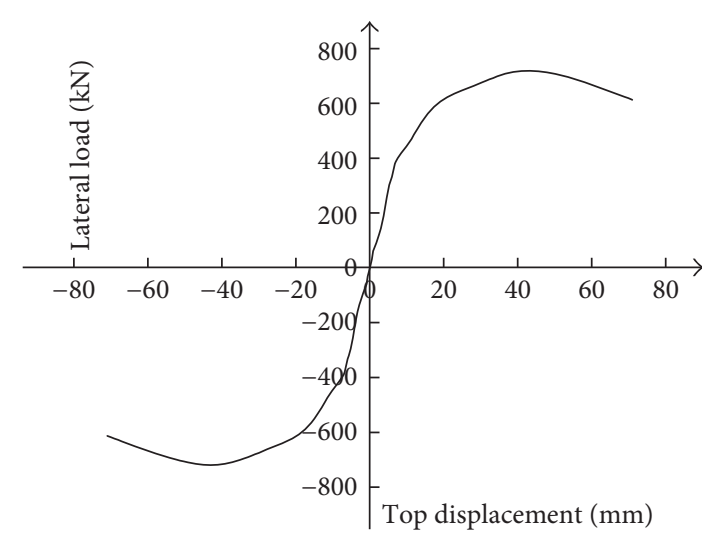

(d)

Figure 14: Hysteresis curves and skeleton curves of RHC-1 and RHC-2. (a) Hysteresis curve of RHC-1. (b) Skeleton curve of RHC-1. (c) Hysteresis curve of RHC-2. (d) Skeleton curve of RHC-2.

TABLE 4: Test results of two specimens.

\begin{tabular}{lcccccccc}
\hline Specimen & $F_{\mathrm{cr}}(\mathrm{kN})$ & $\Delta_{\mathrm{cr}}(\mathrm{mm})$ & $F_{y}(\mathrm{kN})$ & $\Delta_{y}(\mathrm{~mm})$ & $F_{m}(\mathrm{kN})$ & $\Delta_{m}(\mathrm{~mm})$ & $F_{u}(\mathrm{kN})$ & $\Delta_{u}(\mathrm{~mm})$ \\
\hline RHC-1 & 210 & 12.28 & 330 & 18.30 & 610 & 85.44 & 518.50 & 137.70 \\
RHC-2 & 270 & 11.74 & 420 & 13.60 & 718 & 46.49 & 610.30 & 75.50 \\
\hline
\end{tabular}

TABle 5: Comparison of theoretical and test values of displacement ductility.

\begin{tabular}{lccccccc}
\hline \multirow{2}{*}{ Specimens } & \multicolumn{2}{c}{ Yield displacement $(\mathrm{mm})$} & \multicolumn{2}{c}{ Ultimate } & \multicolumn{3}{c}{ Displacement ductility } \\
& Theoretical & Test & Theoretical & Test & Theoretical & Test & Theoretical/test \\
& 15.23 & 18.30 & 133.57 & 137.70 & 8.77 & 7.52 & 1.16 \\
RHC-1 & 11.74 & 13.60 & 68.52 & 75.50 & 5.83 & 5.60 & 1.04 \\
RHC-2 & & &
\end{tabular}

displacements in test inevitably, which leads to the test values larger. However, on the whole, both are in good agreement.

\section{Effect of Unbonded Reinforcement on Yield Displacement and Ultimate Displacement}

In order to study the effect of unbonded reinforcement on yield displacement and ultimate displacement, set RHC-2 as example, Table 6 lists the effect of unbonded reinforcement on yield displacement and ultimate displacement.

Table 6 shows that the effect of unbonded reinforcement on ultimate displacement is more pronounced than that of yield displacement. The reason is that in the yield state, deformation of unbonded reinforcement is small which leads to small effect; however, in the ultimate 
TABLE 6: Effect of unbonded reinforcement on yield displacement and ultimate displacement.

\begin{tabular}{lccccccc}
\hline \multicolumn{3}{l}{ Yield displacement (mm) } & \multicolumn{4}{c}{ Ultimate displacement $(\mathrm{mm})$} \\
\hline$\Delta_{y 1}$ & $\Delta_{y 1} / \Delta_{y}$ & $\Delta_{y 2}$ & $\Delta_{y 2} / \Delta_{y}$ & $\Delta_{u 1}$ & $\Delta_{u 1} / \Delta_{u}$ & $\Delta_{u 2}$ & $\Delta_{u 2} / \Delta_{u}$ \\
9.22 & $78.53 \%$ & 2.52 & $21.47 \%$ & 21.06 & $30.74 \%$ & 47.46 & $69.26 \%$ \\
\hline
\end{tabular}

state, unbonded reinforcement yields and its deformation are large which leads to large effect.

\section{Conclusions and Suggestions}

7.1. Conclusions. In this paper, the curvature and displacement of RHC shear wall are analyzed, and the following conclusions can be drawn:

(1) Considering the effect of confined end-zone and unbonded reinforcement on curvature, yield curvature and ultimate curvature are calculated.

(2) In calculating displacement, assume that the displacement consists of two parts approximately: one part is that the wall generates resisting external force when all reinforcements are bonded, and assume the wall is not a rigid body and another part is that elongation of unbonded reinforcements leads the wall to generate when the wall is RHC shear wall, and assume the wall is a rigid body. Overlay the two parts linearly, and obtain the calculation equation of yield displacement and ultimate displacement. The theoretical and test values are compared. Also, the result shows that theoretical values are slightly smaller than test values, but both are in good agreement on the whole.

(3) According to the theoretical equation, effects of unbonded reinforcement on yield displacement and ultimate displacement are studied. The result shows that the effect of unbonded reinforcement on ultimate displacement is more pronounced than that of yield displacement.

7.2. Suggestions. Only two specimens were applied to verify the displacement ductility in the paper, which was inadequate to convince. Numerous tests considering different parameters should be performed to verify the displacement ductility.

\section{Conflicts of Interest}

The authors declare that there are no conflicts of interest regarding the publication of this paper.

\section{Acknowledgments}

This work was financially supported by the Green Subway Construction Innovation Team of Jinan, National Natural Science Foundation for Young Scientists of China (Grant No. 51708260), the University Natural Science Foundation funded by the Jiangsu Province Government (Grant No. 2016TM045J).

\section{References}

[1] W. B. Hu, X. M. Zhai, and H. B. Jiang, "Study on seismic performance and construction measures optimization of precast fabricated RC integration shear wall," Journal of Building Structures, vol. 37, no. 8, pp. 1-10, 2016.

[2] B. J. Smith, Y. C. Kurama, and M. J. McGinnis, "Perforated hybrid precast shear walls for seismic regions," ACI Structural Journal, vol. 112, no. 3, pp. 359-370, 2015.

[3] J. A. Abdalla, E. I. Saqan, and R. A. Hawileh, "Optimum seismic design of unbonded post-tensioned precast concrete walls using ANN," Computers and Concrete, vol. 13, no. 4, pp. 547-567, 2014.

[4] E. I. Saqan and R. A. Hawileh, "Nondimensional design charts for unbonded, posttensioned, split precast concrete walls," PCI Journal, vol. 55, no. 4, pp. 78-99, 2010.

[5] R. A. Hawileh, E. I. Saqan, and J. A. Abdalla, "Simplified optimum design procedure for special unbonded posttensioned split precast shear walls," Journal of Structural Engineering, vol. 139, no. 2, pp. 294-299, 2013.

[6] B. J. Smith, Y. C. Kurama, and M. J. McGinnis, "Behavior of precast concrete shear walls for seismic regions: comparison of hybrid and emulative specimens," Journal of Structural Engineering, vol. 139, no. 11, pp. 1917-1927, 2013.

[7] F. J. Perez, P. Stephen, and S. Richard, "Experimental lateral load response of unbonded post-tensioned precast concrete walls," ACI Structural Journal, vol. 110, no. 6, pp. 1045-1055, 2013.

[8] S. M. Kang, O. J. Kim, and H. G. Park, "Cyclic loading test for emulative precast concrete walls with partially reduced rebar section," Engineering Structures, vol. 56, pp. 1645-1657, 2013.

[9] A. Solak, Y. S. Tama, S. Yilmaz, and H. Kaplan, "Experimental study on behavior of anchored external shear wall panel connections," Bulletin of Earthquake Engineering, vol. 13, no. 10, pp. 3065-3081, 2015.

[10] S. T. Liang, C. F. Sun, X. J. Zhu, and X. F. Jin, "A precast shear wall horizontal connection node," China Patent 201410269148.5, 2016.

[11] L. J. Si, G. Q. Li, and F. F. Sun, "Calculation method for predicting ductility of reinforced concrete shear walls," Journal of Hebei University of Science and Technology, vol. 27, no. 1, pp. 8-11, 2010.

[12] H. G. Park, S. M. Kang, L. Chung, and D. Lee, "Momentcurvature relationship of flexure-dominated walls with partially confined end-zones," Engineering Structures, vol. 29, no. 1, pp. 33-45, 2007.

[13] X. W. Liang, H. J. Zhao, and M. K. Deng, "Moment-curvature relationship analysis of high-strength concrete shear wall with partially confined end-zone," Journal of Building Structures, no. 2, supplement 2, pp. 62-67, 2009.

[14] Y. G. Chen, Research on Evaluation of Seismic Performance and Design Method about Horizontal Joints in Precast Concrete Shear Wall Structure, Ph.D. thesis, Southeast University, Nanjing, China, 2013.

[15] Q. L. Wang, Y. L. Chi, and D. T. Niu, "Simulation test and analysis of unbonded reinforced concrete beam after corrosion," Building Structure, vol. 31, no. 4, pp. 51-53, 2001.

[16] X. L. Zhang, Research on Reinforced Concrete Beams with Localized Unbonding, M.D. thesis, Shanghai Jiao Tong University, Shanghai, China 2006.

[17] J. H. Mun and K. H. Yang, "Displacement ductility ratio-based flexural design approach of reinforced concrete slender shear walls," Magazine of Concrete Research, vol. 68, no. 8, pp. 409-422, 2016. 


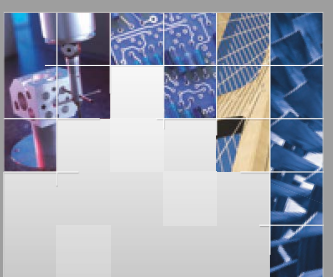

\section{Enfincering}
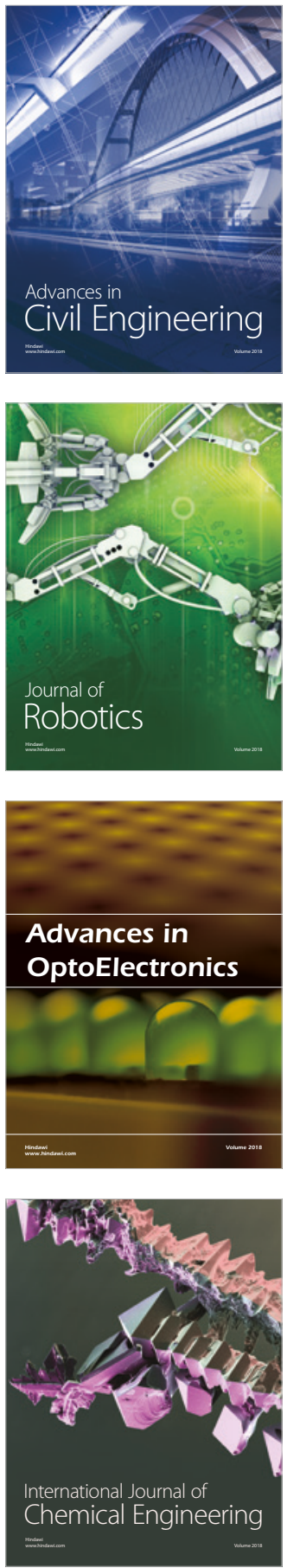

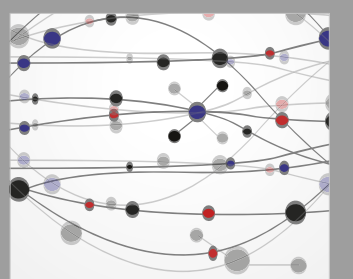

\section{Rotating \\ Machinery}

The Scientific World Journal

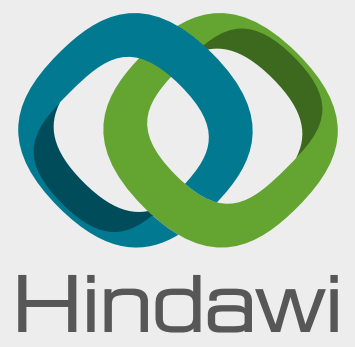

Submit your manuscripts at

www.hindawi.com
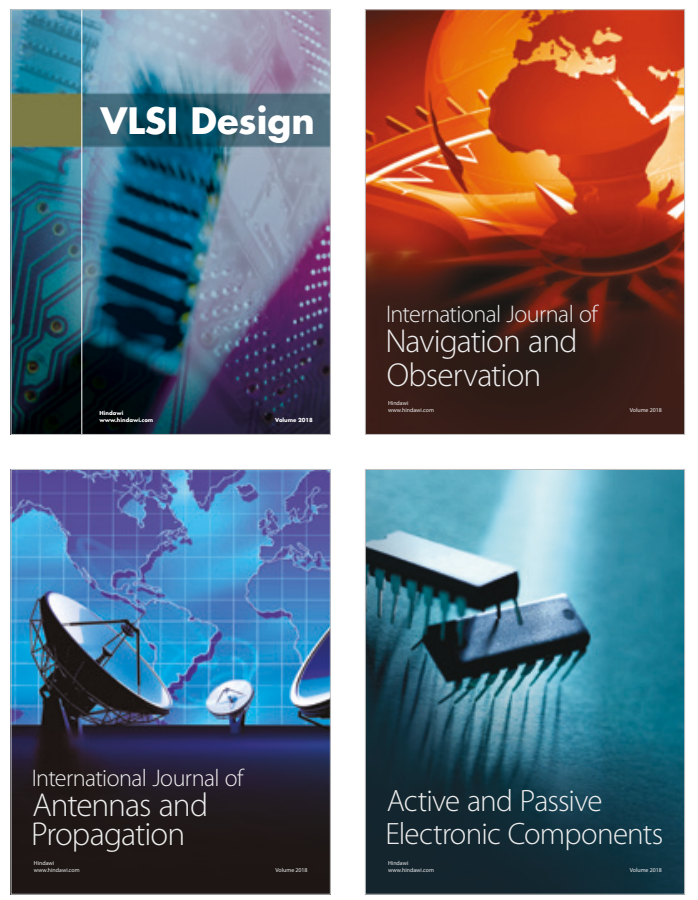
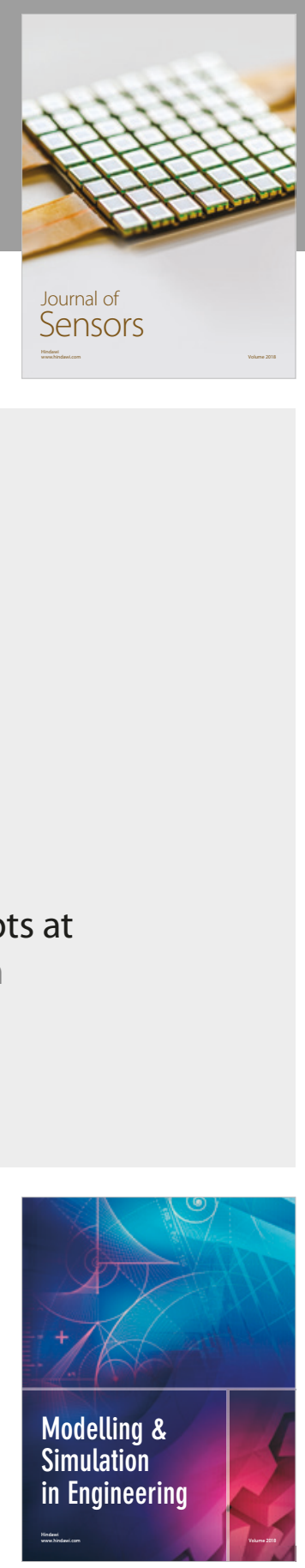

\section{Advances \\ Multimedia}
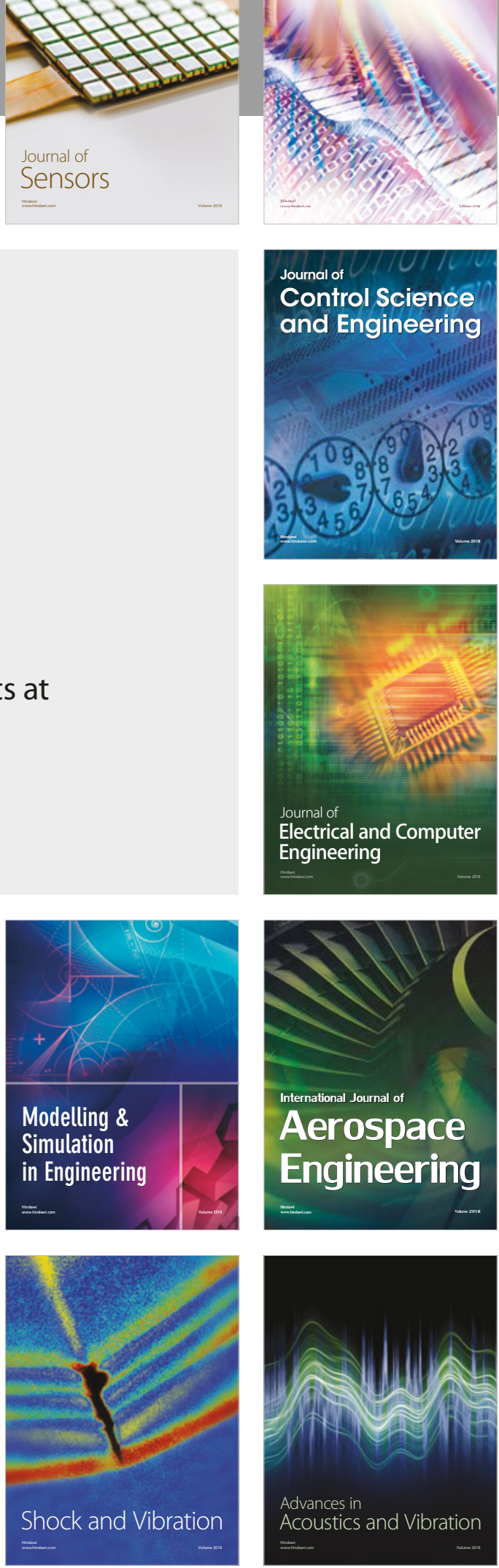